\title{
Abordagem da violência doméstica contra a mulher na atenção primária à saúde: aspectos relacionados à inexperiência médica
}

\author{
Approach to domestic violence against woman in primary health care: aspects related to \\ medical inexperience
}

Enfoque de la violencia doméstica contra las mujeres em atención primaria de salud: aspectos relacionados con la inexperiencia médica

Ana Cláudia Costa Pereira ${ }^{1 *}$, Marina Abreu Corradi Cruz¹, Amanda Rodrigues Rios², Bárbara Lins Silva ${ }^{3}$, Beatrice Gaio de Andrade ${ }^{4}$, Bianca Layne Gomes de Lima ${ }^{1}$, Brendon Arpini Rodrigues², Marcela Reis Fonseca ${ }^{5}$, Tainara Sales Miranda², Adriel Gustavo Lopes¹.

\section{RESUMO}

Objetivo: Refletir acerca da inexperiência médica, na atenção primária, frente aos casos de violência doméstica sofrida pelas mulheres, assim como evidenciar uma grande consequência deste despreparo: a subnotificação dos casos. Métodos: Revisão de 21 publicações científicas indexadas nas seguintes bases eletrônicas de dados: SciELO, LILACS e PubMed. As publicações revisadas abordam artigos dos últimos 10 anos com desenhos metodológicos de natureza descritiva e qualitativa. Resultados: Para iniciar a discussão, foi elucidado o conceito de violência doméstica contra a mulher, destacando a importância da atenção primária à saúde no atendimento às vítimas. Em seguida, são apresentados os fatores complicadores, em particular o silêncio da vítima e o despreparo médico. Por fim, são mostrados os fatores que geram a subnotificação, como a dificuldade de preencher uma notificação obrigatória e a falta de informações sobre as consequências do preenchimento do documento. Considerações finais: A violência doméstica contra a mulher é um complexo problema de saúde pública que envolve a construção, consolidação e normalização da violência em nossa sociedade, e que ecoa no despreparo técnico e educacional dos médicos brasileiros.

Palavras-chave: Violência doméstica, Violência contra a mulher, Atenção primária à saúde, Notificação.

\section{ABSTRACT}

Objective: Reflect on medical inexperience in primary care, in the face of cases of domestic violence suffered by women, as well as showing a great consequence of this unpreparedness: underreporting of cases. Methods: Review of 21 scientific publications indexed in the following electronic databases: SciELO, LILACS and PubMed. The reviewed publications address articles from the last 5 years with methodological designs of a descriptive and qualitative nature. Results: To start a discussion, clarify the concept of domestic violence against a woman, highlight the importance of primary health care in assisting victims. Then, complicating factors are presented, in particular the victim's silence and medical unpreparedness. Finally, the factors that generate underreporting are shown, such as difficulty in keeping a mandatory notification and lack of information on the consequences of completing the document. Final considerations: Domestic violence against women is a complex public health problem that involves the construction, maintenance and normalization of violence in our society, and echoes the technical and educational unpreparedness of Brazilian doctors.

Keywords: Domestic violence, Violence against women, Primary health care, Notification.

${ }^{1}$ Pontifícia Universidade Católica de Minas Gerais (PUC-MG), Betim - MG.

*E-mail: anaclaudiacpereira@gmail.com

${ }^{2}$ Centro Universitário de Caratinga (UNEC), Caratinga - MG.

3Universidade de Itaúna (UIT), Itaúna - MG.

${ }^{4}$ Universidade Federal de São João Del Rei (UFSJ), São João Del Rei - MG.

${ }^{5}$ Faculdade de Ciências Médicas e da Saúde de Juiz de Fora (FCMS-JF), Juiz de Fora - MG. 


\section{RESUMEN}

Objetivo: Reflexionar sobre la inexperiencia médica, en la atención primaria, ante los casos de violencia doméstica que sufren las mujeres, y muestre una gran consecuencia de esta falta de preparación: la subnotificación de casos. Métodos: Revisión de 21 publicaciones científicas indexadas en las siguientes bases de datos electrónicas: SciELO, LILACS y PubMed. Las publicaciones revisadas abordan artículos de los últimos 5 años con diseños metodológicos de naturaleza descriptiva y cualitativa. Resultados: Para comenzar una discusión, aclarar el concepto de violencia doméstica contra una mujer, resaltar la importancia de la atención primaria de salud para ayudar a las víctimas. Luego, se presentan factores complicados, en particular el silencio de la víctima y la falta de preparación médica. Finalmente, se muestran los factores que generan subregistro, como la dificultad para mantener una notificación obligatoria y la falta de información sobre las consecuencias de completar el documento. Consideraciones finales: La violencia doméstica contra las mujeres es un problema complejo de salud pública que implica la construcción, el mantenimiento y la normalización de la violencia en nuestra sociedad, y se hace eco de la falta de preparación técnica y educativa de los médicos brasileños.

Palabras clave: Violencia doméstica, Violencia contra la mujer, Atención primaria de salud, Notificación.

\section{INTRODUÇÃO}

Define-se Violência Doméstica e Familiar Contra a Mulher como qualquer ato praticado em desfavor desta, dentro do ambiente doméstico, que resulte em morte, lesões físicas, sofrimento sexual, psicológico, moral ou patrimonial - desde que praticado por pessoa que conviva, tenha convivido ou que, ainda, possua qualquer relação de afeto com a vítima, independente de coabitação (SANTOS WJ, et al., 2018; LOURENÇO LM e COSTA DP, 2020).

Alguns avanços já foram feitos, dentre eles, a aprovação da Lei Maria da Penha, de 07 de agosto de 2006, que prevê pena para os agressores envolvidos em situações de violência doméstica, e representa um apelo para assegurar à mulher o direito a sua integridade física, psíquica, sexual e moral (MACHADO MES, et al., 2017). Outro progresso refere-se a instituição da ficha de notificação compulsória, tanto no serviços públicos como privados, de casos de violência contra as mulheres, que deve ser preenchida pelo profissional de saúde (MACHADO DF, et al., 2016).

De acordo com os dados notificados, aproximadamente 205 mil mulheres brasileiras são vítimas de agressões no período de um ano. Foram protocolados, em 2015, 223.796 atendimentos a mulheres vítimas de violência, dado este apontado pelo Registro do Sistema de Informação de Agravos de Notificação.

Duas em cada três das vítimas (147.691) careceram de atendimento em unidade de saúde. O total de vítimas de feminicídio aumentou $21 \%$ em uma década, saindo de 3937 casos em 2005, para uma soma de 4762 em 2015 (SANTOS WJ, et al., 2018).

A taxa de prevalência da violência doméstica ao longo da vida para mulheres que se apresentam em várias especialidades médicas está entre 38 e $59 \%$. Além disso, das mulheres que foram mortas por seu parceiro íntimo, $45 \%$ frequentaram um hospital para tratamento de lesões relacionadas à violência doméstica nos dois anos anteriores à sua morte.

Os profissionais de saúde, portanto, estão em uma posição única para identificar e fornecer assistência crítica às mulheres que sofrem de violência doméstica (SPRAGUE S, et al., 2018).A violência contra mulher vem ganhando visibilidade pela sociedade por ser um significativo problema de saúde pública com necessidade de intervenção.

Situações de violências podem gerar diversos problemas que afetam a saúde, tanto de forma aguda como crônica, culminando em busca com maior frequência por serviços de saúde, dentre eles a Atenção Primária, que atua como porta de entrada para serviços especializados. Logo, cabem aos profissionais desses atendimentos, acolher e determinar a causa desse sofrimento (BORBUREMA TLR, et al., 2017; SANTOS WJ, et al., 2018). 
A Atenção Primária à Saúde (APS) e seus serviços são imprescindíveis para a detecção de situações de violência contra as mulheres, visto que estabelecem uma ampla cobertura e uma relação próxima da vítima no local do fato violento, sendo potencialmente capaz de reconhecer e acolher mulheres que vivenciam agressão (ARBOIT J, et al., 2018).

É um direito da mulher o acolhimento humanizado e diferenciado pelo trauma sofrido. O acolhimento consiste em uma relação médico paciente além das convencionais, requer empatia, escuta qualificada e cuidado (LOPES JDS, 2016). Por se configurar como porta de entrada para o atendimento, o médico da Atenção Primária, responsável por fazer o primeiro contato com o paciente, deve pautar seu atendimento no Método Clínico Centrado na Pessoa, valorizando uma atuação holística e empática, uma vez que é responsável pelo bem-estar geral da comunidade em que trabalha, além de prestar assistência continuada, baseada nos atributos essenciais da APS, como a longitudinalidade, a integralidade e a coordenação. Dessa forma, o médico de família tem função privilegiada, atuando na precaução, detecção e acompanhamento dos casos (SILVA AR, 2018).

Todavia, ainda que a APS assegure o acesso ao cuidado dessas mulheres, não se configura, ainda, suficiente. Existe conhecimento em relação à complexidade destas demandas, porém o sistema carece de ferramentas eficientes para compor a assistência e otimizá-la em cuidados intersetoriais e interdisciplinares (OLIVEIRA MT e FERIGATO SH, 2019).

No Brasil, muitos profissionais que lidam diretamente com mulheres em situação de violência doméstica revelam despreparo para atendimento eficaz (LEITE AC e FONTANELLA BJB, 2019). Em meio aos obstáculos e desafios encontrados no cuidado com essas mulheres, ressalta-se o sentimento de insegurança, falhas na formação profissional, ausência de capacitação, falta de qualificação e conhecimento para manejar os casos, além da dificuldade de ampliar a atenção para além das queixas biológicas, praticando uma abordagem voltada para o contexto biopsicossocial da paciente (SANTOS WJ, et al., 2018).

O aperfeiçoamento de técnicas e uma melhor qualificação e treinamento dos profissionais de saúde devem ser considerados prioridade, dado que a identificação dos casos de violência doméstica contra a mulher demanda elevada sensibilidade, conscientização e confidencialidade (SIGNORELLI MC, et al., 2018). Como consequência do despreparo profissional, é comum que os (as) médicos (as) não notifiquem os casos de violência, gerando expressiva subnotificação (BORBUREMA TLR, et al., 2017). A falta do preenchimento de todos os campos da ficha de notificação faz com que seus dados sejam restringidos de forma epidemiológica, mesmo quando a notificação é realizada (LEITE AC e FONTANELLA BJB, 2019).

Considerando as complexas variantes da violência doméstica contra a mulher e a importância de um cuidado adequado, este estudo tem como objetivo ponderar acerca da inexperiência médica frente a tais situações de vulnerabilidade social sofrida pelas mulheres, bem como evidenciar a maior consequência deste despreparo: a subnotificação dos casos. Justifica-se em um contexto de ressaltar a reflexão da importância da formação e prática dos profissionais da saúde no que diz respeito às tomadas de decisão frente aos casos relatados.

\section{MÉTODOS}

Este estudo constitui uma revisão bibliográfica de caráter descritiva e qualitativa, desenvolvida com produção científica indexada nas seguintes bases eletrônicas de dados: SciELO, LILACS e PubMed. A coleta de dados foi realizada no período de 18 a 20 de abril de 2020. Foram utilizados os seguintes descritores: violência doméstica, atenção primária à saúde, capacitação profissional e mulheres. A seleção de artigos a serem incluídos nesta revisão baseou-se no seguinte critério: artigos de revisão de narrativas que avaliam capacitação profissional dos médicos atuantes na atenção primária à saúde frente à violência doméstica contra mulheres (Quadro 1).

Foi definido como critério de inclusão: artigos publicados nos últimos 10 anos. A busca foi limitada a estudos em inglês, espanhol e português. Foi considerado como objeto de estudo mulheres de todas as faixas etárias que sofreram algum tipo de violência doméstica. Os achados foram selecionados por meio da leitura de seus resumos (Figura 1). 


\section{Revista Eletrônica Acervo Saúde / Electronic Journal Collection Health | ISSN 2178-2091}

Quadro 1 - Relação entre autores, língua, objetivos e principais resultados dos artigos selecionados no estudo.

\begin{tabular}{|c|c|c|c|}
\hline Autores & Língua & Objetivos & Principais resultados \\
\hline $\begin{array}{l}\text { MENDONÇA } \\
\text { CS, et al., } \\
\quad 2018 .\end{array}$ & Português & $\begin{array}{l}\text { Revisou de forma integrativa a literatura, analisando a } \\
\text { produção científica nacional acerca da temática da } \\
\text { violência na Atenção Primária à Saúde. }\end{array}$ & $\begin{array}{l}\text { Observou-se a invisibilidade dos casos de violências pelos serviços de atenção } \\
\text { primária, mostrando uma necessidade na reorganização do processo de Atenção } \\
\text { Primária no Brasil e também da queixa, conduta, objetivando a abordagem } \\
\text { sociocultural e ampliada dos variados grupos de indivíduos em situação de violência. }\end{array}$ \\
\hline $\begin{array}{l}\text { MACHADO } \\
\text { DF, et al., } \\
2016 .\end{array}$ & Português & $\begin{array}{l}\text { Descrever as correntes teóricas explicativas da violência } \\
\text { contra a mulher e as formas de intervenção apreendidas } \\
\text { durante a educação médica. }\end{array}$ & $\begin{array}{l}\text { Revelou o aprendizado de quatro aspectos importantes das implicações em relação } \\
\text { à saúde das mulheres: influências socioculturais e psicossociais no processo saúde- } \\
\text { doença; a relevância da integralidade no atendimento; o papel como facilitadora da } \\
\text { estratégia de saúde da família na identificação e acompanhamento dos casos; e } \\
\text { violência contra mulher como um problema de saúde pública, pertinente à educação } \\
\text { médica. }\end{array}$ \\
\hline $\begin{array}{l}\text { LOURENÇO } \\
\text { LM e COSTA } \\
\text { DP, } 2020 .\end{array}$ & Português & $\begin{array}{l}\text { Revisou a literatura de forma sistemática, abordando as } \\
\text { consequências, para a saúde da mulher, da violência } \\
\text { doméstica entre parceiros íntimos. }\end{array}$ & $\begin{array}{l}\text { Os resultados sugerem uma expressiva relação entre a violência entre parceiros } \\
\text { íntimos e agravos à saúde da mulher, especialmente em relação à saúde mental. } \\
\text { Considerou-se a importância da criação de intervenções para minimizar esses } \\
\text { agravos. }\end{array}$ \\
\hline $\begin{array}{l}\text { PEREIRA- } \\
\text { GOMES N, } \\
\text { et al., } 2015 .\end{array}$ & Português & $\begin{array}{l}\text { Objetivou compreender os significados que são atribuídos } \\
\text { pelos profissionais da saúde em relação ao apoio social } \\
\text { dado à mulher vítima de violência conjugal. }\end{array}$ & $\begin{array}{l}\text { Observou relação entre as ameaças dos companheiros e a dependência econômica, } \\
\text { justificando encaminhamentos intersetoriais e a necessidade de inserção da mulher } \\
\text { em programas que gerem renda. }\end{array}$ \\
\hline $\begin{array}{l}\text { SALIBA O, et } \\
\text { al., 2007. }\end{array}$ & Português & $\begin{array}{l}\text { Verificou a responsabilidade dos profissionais de saúde } \\
\text { em notificar a violência doméstica e suas possíveis } \\
\text { implicações éticas e legais, as quais estão sujeitos. }\end{array}$ & $\begin{array}{l}\text { Observou que os profissionais de saúde possuem a obrigação de notificar os casos } \\
\text { de violência de seu conhecimento, podendo até responder legalmente, caso omita a } \\
\text { notificação. }\end{array}$ \\
\hline $\begin{array}{l}\text { LOPES JDS, } \\
2016 .\end{array}$ & Português & $\begin{array}{l}\text { Verificar estudos sobre o amparo à mulher vítima de } \\
\text { violência doméstica, que garantam seus direitos à saúde } \\
\text { humanizada e integral, observando ainda, qual o papel do } \\
\text { profissional de saúde na defesa desses direitos. }\end{array}$ & $\begin{array}{l}\text { Observou a falta de humanização dos profissionais no atendimento de vítimas de } \\
\text { violência doméstica. Demonstra a falta de capacitação e orientação dos profissionais } \\
\text { diante à situação, sendo assim, falhos em ajudar a garantir a essas mulheres, seus } \\
\text { direitos integrais à saúde. }\end{array}$ \\
\hline $\begin{array}{l}\text { USTA J e } \\
\text { TALEB R, } \\
2014 .\end{array}$ & Inglês & $\begin{array}{l}\text { Apresenta a magnitude do problema da violência } \\
\text { doméstica no “mundo árabe”. Destaca o papel do médico } \\
\text { na Atenção Primária no enfrentamento desse problema, } \\
\text { fornecendo passos práticos, que podem orientar o clínico, } \\
\text { oferecendo um serviço abrangente e culturalmente } \\
\text { sensível aos sobreviventes de violência doméstica. }\end{array}$ & $\begin{array}{l}\text { A violência doméstica é frequentemente encontrada na atenção básica e precisa ser } \\
\text { tratada adequadamente. Expressar empatia, reconhecimento e apoio contínuo são } \\
\text { os elementos mais importantes do atendimento imediato prestado aos pacientes que } \\
\text { relataram o abuso. Segurança deve ser avaliada e, se o risco de abuso estiver } \\
\text { presente, o planejamento de segurança deve ser elaborado. O aconselhamento } \\
\text { pode fortalecer o senso de autoestima do sobrevivente e o sentimento de apoio e } \\
\text { assistência contínua. Pode ser necessário encaminhamento para assistência } \\
\text { psicológica e organizações que trabalham com mulheres que sofreram abuso. }\end{array}$ \\
\hline
\end{tabular}

REAS/EJCH | Vol.12(10) | e4580 | DOI: https://doi.org/10.25248/reas.e4580.2020 Página 4 de 11 


\section{Revista Eletrônica Acervo Saúde / Electronic Journal Collection Health | ISSN 2178-2091}

\begin{tabular}{|c|c|c|c|}
\hline Autores & Língua & Objetivos & Principais resultados \\
\hline $\begin{array}{l}\text { VIEIRA EM e } \\
\text { HASSE M, } \\
2017 \text {. }\end{array}$ & Português & $\begin{array}{l}\text { Objetivou identificar como os profissionais envolvidos na } \\
\text { atenção às mulheres que estiveram em situação de } \\
\text { violência em uma rede intersetorial, entendem os } \\
\text { atendimentos que realizam. }\end{array}$ & $\begin{array}{l}\text { Foram detectadas percepções fragmentadas e estereotipadas sobre a temática com } \\
\text { necessidade de melhorar a infraestrutura existente e humanizar os profissionais que } \\
\text { participam desse tipo de atendimento. Ressaltar a necessidade de criação de } \\
\text { serviços específicos de prevenção e revelar um descompasso entre intenção política } \\
\text { no enfrentamento da violência e a realidade do que foi estudado. }\end{array}$ \\
\hline $\begin{array}{l}\text { OLIVEIRA } \\
\text { AMN, et al., } \\
2015 .\end{array}$ & Português & $\begin{array}{l}\text { Identificar a percepção dos profissionais atuante em } \\
\text { equipes de saúde da família no programa de prevenção à } \\
\text { violência, em relação às intervenções primárias, com o } \\
\text { objetivo de evitar a violência intrafamiliar. }\end{array}$ & $\begin{array}{l}\text { Identificou-se que os profissionais já conhecem as intervenções primárias, } \\
\text { observando que algumas já estão sendo utilizadas no trabalho multiprofissional. }\end{array}$ \\
\hline $\begin{array}{l}\text { MACHADO } \\
\text { MÊS, et al., } \\
2017 .\end{array}$ & Português & $\begin{array}{l}\text { Identificar como os profissionais de saúde percebem a } \\
\text { violência contra a mulher. }\end{array}$ & $\begin{array}{l}\text { Foram encontradas dificuldades na compreensão de conceitos, como notificação e } \\
\text { denúncia por parte dos profissionais. Foi observado também um conhecimento } \\
\text { superficial sobre a Lei Maria da Penha, o que pode apresentar prejuízos nos } \\
\text { processos de encaminhamentos e orientações. }\end{array}$ \\
\hline $\begin{array}{l}\text { GARCIA LP, } \\
\text { et al., } 2016 .\end{array}$ & Português & $\begin{array}{l}\text { Identificar os possíveis fatores envolvidos no atendimento } \\
\text { por violência doméstica e familiar, em vítimas que foram } \\
\text { atendidas em serviços de urgência e emergência no } \\
\text { Brasil. }\end{array}$ & $\begin{array}{l}\text { O consumo de bebida alcoólica foi fortemente associado como fator crítico na } \\
\text { violência doméstica e familiar. A avaliação de maior ocorrência em dias e horas } \\
\text { demonstra uma necessidade de adequação dos serviços de atendimento prestados } \\
\text { às vítimas. }\end{array}$ \\
\hline $\begin{array}{l}\text { ARBOIT J, et } \\
\text { al., } 2018 .\end{array}$ & Português & $\begin{array}{l}\text { Reconhecer a violência doméstica que abrange o cenário } \\
\text { rural no Brasil, assim como entender as práticas de } \\
\text { cuidado que estão sendo aplicadas nesse ambiente. }\end{array}$ & $\begin{array}{l}\text { Observou-se que as agentes comunitárias de saúde da região utilizavam de técnicas } \\
\text { como a escuta ativa e o diálogo para lidarem com a situação. Foi observada a } \\
\text { necessidade de aumentar a qualificação e a intersetorialidade da equipe, afim de } \\
\text { que haja uma melhor resolução da violência doméstica nessas comunidades. }\end{array}$ \\
\hline $\begin{array}{l}\text { OLIVEIRA } \\
\text { MT e } \\
\text { FERIGATO } \\
\text { SH, } 2019 .\end{array}$ & Português & $\begin{array}{l}\text { Identificar, relacionar e analisar a importância da terapia } \\
\text { ocupacional no cuidado da mulher vítima de violência } \\
\text { doméstica. }\end{array}$ & $\begin{array}{l}\text { Notou-se que a terapia ocupacional exerce um papel importante no cuidado da } \\
\text { mulher que sofre com a violência doméstica. Além de ter uma ampla gama de } \\
\text { metodologias, a terapia ocupacional atua na quebra do ciclo da violência. }\end{array}$ \\
\hline $\begin{array}{l}\text { SILVA AR, } \\
2018 \text {. }\end{array}$ & Português & $\begin{array}{l}\text { Observar o papel do médico de família no combate e } \\
\text { controle da violência doméstica. }\end{array}$ & $\begin{array}{l}\text { Ressalta a importância de profissionais que saibam intervir, abordar e diagnosticar a } \\
\text { violência doméstica levando sempre em consideração a importância, o sigilo e } \\
\text { confidencialidade médica. }\end{array}$ \\
\hline $\begin{array}{l}\text { LEITE AC e } \\
\text { FONTANELL } \\
\text { A BJB, } 2019 .\end{array}$ & Português & $\begin{array}{l}\text { Contribuir para compreender as dificuldades subjetivas de } \\
\text { notificar a violência doméstica contra a mulher por } \\
\text { profissionais da atenção primária à saúde no Brasil. }\end{array}$ & $\begin{array}{l}\text { As dificuldades de notificação relacionam-se a permanência de resistências culturais, } \\
\text { com a sobrevalorização pelos profissionais de suas tradicionais funções terapêuticas } \\
\text { e com a dificuldade da vítima em expor a violência. Além disso, a notificação causa } \\
\text { questionamentos éticos, ansiedades e dúvidas técnicas nos profissionais. Esses }\end{array}$ \\
\hline
\end{tabular}

REAS/EJCH | Vol.12(10) | e4580 | DOI: https://doi.org/10.25248/reas.e4580.2020 Página 5 de 11 


\section{Revista Eletrônica Acervo Saúde / Electronic Journal Collection Health | ISSN 2178-2091}

\begin{tabular}{|c|c|c|c|}
\hline Autores & Língua & Objetivos & Principais resultados \\
\hline & & & $\begin{array}{l}\text { fatores, somados à usual sobrecarga de trabalho, podem ajudar a perpetuar a } \\
\text { subnotificação dos casos. }\end{array}$ \\
\hline $\begin{array}{l}\text { SANTOS } \\
\text { WJ, et al., } \\
2018 . \\
\end{array}$ & Português & $\begin{array}{l}\text { Compreender as representações sociais de profissionais } \\
\text { da Atenção Primária à Saúde sobre violência contra a } \\
\text { mulher perpetrada por parceiro íntimo. }\end{array}$ & $\begin{array}{l}\text { O estudo demonstrou que a violência contra as mulheres é legitimada, aceita e } \\
\text { tolerada nas falas dos participantes, como algo imputado/inerente à mulher. }\end{array}$ \\
\hline $\begin{array}{l}\text { BORBUREM } \\
\text { A TLR, et al., } \\
2017 .\end{array}$ & Português & $\begin{array}{l}\text { Investigar o registro dos tipos de violência sofridos e as } \\
\text { condutas tomadas, por profissionais de saúde, incluindo a } \\
\text { notificação, frente ao relato de situação de violência por } \\
\text { mulheres em contexto de vulnerabilidade social atendidas } \\
\text { na Atenção Primária à Saúde. }\end{array}$ & $\begin{array}{l}\text { Do total de } 769 \text { prontuários, } 3,77 \% \text { havia relato de violência: } 45 \% \text { física e } 24 \% \\
\text { psicológica. O principal agressor foi o parceiro íntimo (41\%) e } 58 \% \text { dos relatos foram } \\
\text { registrados por médicos, em Centros de Saúde. Houve algum tipo de conduta para } \\
89 \% \text { dos casos (medicação, encaminhamento ou retorno). Apenas } 7 \% \text { dos casos } \\
\text { foram notificados. Os dados desse estudo sugerem que possa haver sub-registro } \\
\text { das situações de violência. }\end{array}$ \\
\hline $\begin{array}{l}\text { RODRIGUE } \\
\text { Z-BLANES } \\
\text { GM, et al., } \\
2017 .\end{array}$ & Espanhol & $\begin{array}{l}\text { Determinar a frequência e os fatores associados a } \\
\text { realização de perguntas para a detecção de violência por } \\
\text { parceiro íntimo na atenção básica e descrever as } \\
\text { principais ações realizadas nos casos identificados. }\end{array}$ & $\begin{array}{l}67,2 \% \text { dos participantes indicaram que perguntaram sobre violência por parceiro } \\
\text { íntimo na consulta, sendo as ações mais frequentes: o encaminhamento para outros } \\
\text { serviços, o aconselhamento individual e o fornecimento de informações. A realização } \\
\text { de perguntas aumenta conforme os profissionais se sentem treinados e recebem um } \\
\text { protocolo de manejo de casos. }\end{array}$ \\
\hline $\begin{array}{l}\text { SPRAGUE } \\
\text { S, et al., } \\
2018 .\end{array}$ & Inglês & $\begin{array}{l}\text { Identificar e sintetizar a literatura que avalia os programas } \\
\text { de educação em violência múltipla por parceiro íntimo } \\
\text { para profissionais de saúde para identificar áreas-chave } \\
\text { com potenciais recomendações baseadas em evidências } \\
\text { e focar em futuras prioridades de pesquisa. }\end{array}$ & $\begin{array}{l}\text { Dos } 65 \text { estudos elegíveis, 55\% relataram eficácia positiva do programa. Programas } \\
\text { eficazes frequentemente relataram o uso de componentes de treinamento online, } \\
\text { fornecidos por um educador/especialista ou médico/cirurgião treinado em violência } \\
\text { múltipla por parceiro íntimo. A inclusão de um protocolo de tratamento e recursos } \\
\text { para pacientes e profissionais de saúde com mais de cinco sessões de treinamento } \\
\text { e duração de até uma hora cada demonstram resultados heterogêneos e que uma } \\
\text { ampla variedade de metodologias tem sido usada para avaliar sua eficácia. }\end{array}$ \\
\hline $\begin{array}{l}\text { LEITE FMC, } \\
\text { et al., } 2018 .\end{array}$ & Português & $\begin{array}{l}\text { Verificar eventuais associações entre características do } \\
\text { comportamento e das condições sociais e história de } \\
\text { violência do parceiro íntimo. }\end{array}$ & $\begin{array}{l}\text { O estudo encontrou } \\
\text { entre as seguintes características do parceiro e maior histórico de violência íntima: } \\
\text { não ter ocupação, ser fumante, ter alta ingesta de bebida alcoólica, histórico de } \\
\text { negativa de uso do preservativo e ter escolaridade de até oito anos. }\end{array}$ \\
\hline $\begin{array}{l}\text { SIGNORELL } \\
\text { I MC, et al., } \\
2018 .\end{array}$ & Inglês & $\begin{array}{l}\text { Explorar o manejo da violência doméstica na APS } \\
\text { brasileira através do estudo das ações de uma unidade } \\
\text { básica de saúde. }\end{array}$ & $\begin{array}{l}\text { Foi observada uma grande disparidade entre as políticas públicas federais, sua } \\
\text { aplicabilidade no nível local e o papel primordial do ACS na promoção de uma } \\
\text { conexão entre os principais elos envolvidos no manejo da VD: as mulheres, os } \\
\text { profissionais e o sistema de saúde. }\end{array}$ \\
\hline
\end{tabular}

Fonte: Pereira ACC, et al., 2020.

REAS/EJCH | Vol.12(10) | e4580 | DOI: https://doi.org/10.25248/reas.e4580.2020 Página 6 de 11 
Figura 1 - Fluxograma demonstrando as etapas de seleção de artigos para compor a revisão bibliográfica.

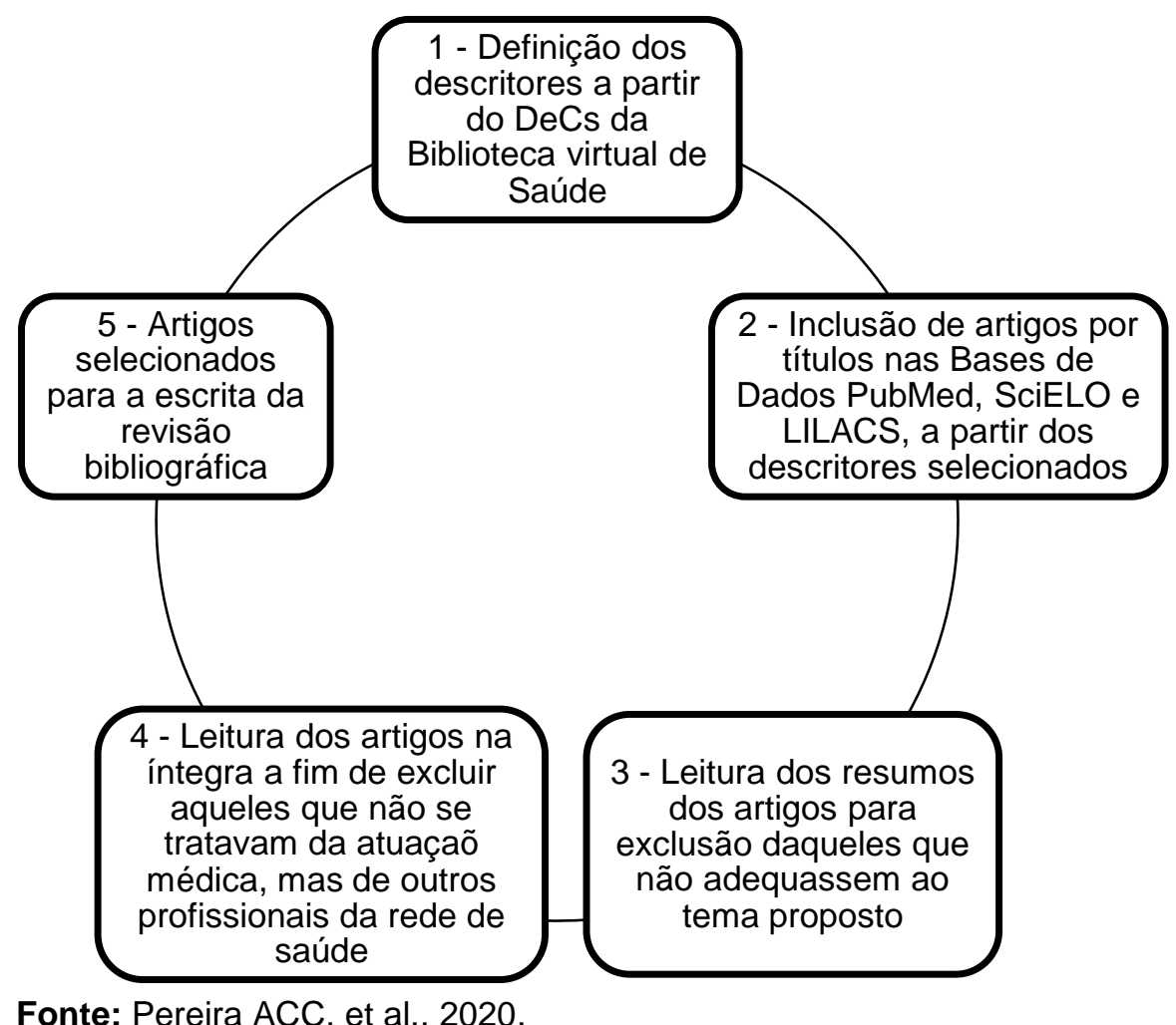

\section{RESULTADOS E DISCUSSÃO}

No total, foram selecionadas 21 referências para a construção desse artigo, organizadas conforme os interesses da argumentação pretendida. Destes, foram identificados e colocados em pauta no presente estudo aspectos recorrentes, como a alta prevalência do tema, em contraponto a marcante dificuldade de abordagem da questão no cotidiano do (a) médico(a).

A violência doméstica constitui um problema complexo, com alicerces profundos nos costumes sociais e na perpetuação das desigualdades entre os diversos segmentos populacionais (LEITE FMC, et al., 2018). Vários estudos trazem a violência doméstica contra a mulher como uma realidade ainda negligenciada pela sociedade, até mesmo no campo de saúde, embora tenha começado a ganhar visibilidade nos últimos anos (SILVA AR, 2018; MENDONÇA CS, et al., 2020).

Sendo assim, as políticas públicas recomendam que $\mathrm{o}$ atendimento às mulheres vítimas de violência deve ser realizado de forma multissetorial, sendo um deles a rede básica de saúde, posto que a violência contra a mulher ocasiona forte impacto sobre a saúde e é, ainda, uma questão de caráter social, requerendo assim a participação dos setores da segurança pública e assistência social, por exemplo (SANTOS WJ, et al., 2018; PEREIRA-GOMES N, et al., 2015).

Um estudo de casos e controles realizado na rede de urgência e emergência em 25 cidades brasileiras em relação aos atendimentos de vítimas da violência domésticas ressalta que um dos fatores analisados e de grande relevância foi à busca pela vítima de um serviço anterior pela mesma ocorrência, antes de procurar unidades mais complexas, corroborando que muitas mulheres não tiveram o acolhimento apropriado no primeiro local que buscaram o que pode elucidar o despreparo dos serviços para o atendimento a estas vítimas, assim como o protocolo de atendimento nesse cenário (GARCIA LP, et al., 2016).

Outro complicador é o motivo da vinda da usuária do serviço à APS. As mulheres buscam a unidade principalmente devido às consequências da violência sofrida, e não para relatá-la a um(a) profissional 
(BORBUREMA TLR, et al., 2017). Muitas delas apresentam múltiplas queixas, repetidas e crônicas, incluindo cefaleia, alteração do sono, ansiedade e depressão.

Outros sinais e sintomas que podem sugerir violência são: lesões e contusões de várias cores, indicando que ocorrem regularmente; problemas repetidos de saúde reprodutiva, como abortos repetidos; problemas psicológicos ou comportamentais, como transtorno de estresse pós-traumático, transtornos de ansiedade, abuso de substâncias, comportamento suicida, distúrbios somatizantes e distúrbios alimentares (USTA J e TALEB R, 2014).

Caso o(a) médico(a) não esteja atento aos estigmas da violência doméstica, ele(a) pode deixar de abordar o problema ou não desempenhar seu papel de forma integrativa, não relacionando informações adquiridas na anamnese e exame físico com a situação de violência (BORBUREMA TLR, et al., 2017).

A fim de atender às demandas dessas mulheres, que são muitas, complexas, e podem vir sob a forma de agenda oculta, se constata que os(as) médicos (as) precisam estar capacitados(as) para desenvolverem uma prática assistencial holística, empática generalista e interprofissional. A sensibilidade e disponibilidade da arte de ouvir o(a) paciente, além de aprimoramento e qualificação do(a) profissional para acolher as vítimas são imperativos para a identificação e mobilização de recursos frente à violência (OLIVEIRA MT e FERIGATO $\mathrm{SH}, 2019)$.

Entretanto, o presente estudo constatou que grande parte dos profissionais da área de saúde, se não quase totalidade, confessa dúvidas diante do seu papel, além de expressar a falta de preparo para abordar tais casos.

Devido à falta de qualificação, frequentemente transferem a responsabilidade do cuidado, contribuindo de forma indireta para a sonegação da violência. Outro ponto a se ponderar é a expressão subjetiva ao registrarem os casos em prontuários e a falta de conhecimento acerca de protocolos para o registro (BORBUREMA TLR, et al., 2017).

Ademais, também é fundamental uma abordagem multiprofissional, envolvendo assistentes sociais, psicólogos e, principalmente, Agentes Comunitários de Saúde, os quais vivenciam e conhecem melhor a realidade da comunidade, o que permite detectar com maior facilidade quando há casos de violência intrafamiliar. Todavia, observa-se dificuldade de articulação entre os setores de continuidade do cuidado, em ações de referência e contrarreferência, o que se torna uma barreira para uma atuação mais eficaz e resolutiva (OLIVEIRA AMN, et al., 2014).

É importante a valorização dos casos de violência contra a mulher, não só por meio do registro e da notificação, mas por uma abordagem intersetorial e de integração com o serviço social e psicológico. Observase que os profissionais apresentam pouco conhecimento sobre outros serviços e não há fluxograma estabelecido. Esses fatos comprometem o pleno funcionamento da rede e a mulher não tem sua demanda atendida. (VIEIRA EM e HASSE M, 2017).

Foram identificados na literatura científica vários dados que contribuem significativamente para essa realidade, que vão desde aspectos técnicos até ético-culturais (LEITE AC e FONTANELLA BJB, 2019). Estes aspectos impactam ainda mais o médico da atenção primária, pois este tem a primazia na identificação e prevenção, assim como na condução de casos de violência doméstica, uma vez que ele(a) se encontra mais próximo da comunidade e com isso tem um vínculo já bem estabelecido com as usuárias.

Dessa forma, é essencial que o(a) médico(a) e os profissionais estejam aptos(as) para prestar o atendimento, respeitando o sigilo e garantindo o cuidado contínuo de suas vítimas, bem como oferecendo um ambiente seguro para elas exporem suas queixas (SANTOS WJ, et al., 2018).

Referente aos aspectos éticos e culturais, esses são observados no atendimento e desfecho dados às queixas de violência doméstica. $O(A)$ médico(a) da Atenção Primária à Saúde pode ter sua conduta impactada por seus conhecimentos prévios, advindos do senso comum, de que o manejo para o caso deva ser dado por outros profissionais da rede de saúde ou que estejam a cargo das instituições policiais. Pode ainda julgar, por interferência cultural, que a violência doméstica é uma situação da vida privativa dos envolvidos, deixando de 
perguntar sobre sua ocorrência ou de tomar condutas ativas caso observe essa queixa (LEITE AC e FONTANELLA BJB, 2019).

Além disso, é válido refletirmos a respeito do ambiente no qual está sendo feita essa consulta, visto que a Estratégia de Saúde da Família promove a proximidade longitudinal com todos os membros familiares e isso possivelmente acrescenta ainda mais embaraços a esta avaliação. Os profissionais expõem-se a medos e possibilidades de ameaças físicas e psicológicas, o que provavelmente influenciam suas subjetividades enquanto avaliam. (LEITE AC e FONTANELLA BJB, 2019)

Foram constatados ainda inaptidão educacional e técnica tanto em sua formação acadêmica, quanto no ambiente de trabalho, gerando no(as) médicos(as) um sentimento de insegurança e despreparo para rastrear, identificar e construir políticas públicas voltadas à violência doméstica contra a mulher (SANTOS WJ, et al., 2018).

Em um estudo realizado no município de Guanambi, Bahia, com doze profissionais de saúde, constatouse que apesar de os profissionais apresentarem conhecimento acerca da definição do conceito de violência, o que é essencial para o reconhecimento/identificação do agravo e enfrentamento deste tipo de violência, exibiram-se dificuldades na compreensão de conceitos fundamentais como denúncia e notificação (MACHADO MES, et al., 2017). Consequentemente, esse quadro pode gerar negligência de assistência e cuidados por parte dos médicos, levando a uma subestimação da violência e por final subnotificação (BORBUREMA TLR, et al., 2017).

Além disso, no campo legislação médica o código de Ética Médica traz que um dos deveres do médico é preservar a integridade e dignidade do seu paciente; no artigo 49, encontra-se que: "É vedado ao médico: Participar da prática de tortura ou outras formas de procedimentos degradantes, desumanos ou cruéis, ser conivente com tais práticas ou não as denunciar quando delas tiver conhecimento". Com isso, o médico tem como responsabilidade jurídica denunciar casos de violência doméstica contra a mulher e, se não fizer, pode responder por omissão e ser penalizado (SALIBA O, et al., 2007).

No que diz respeito a programas de educação permanente na área, estudos enaltecem que há falta de oferta e de participação por parte dos municípios, mostrando a fragilidade dos serviços prestados na Atenção Primária à Saúde, prejudicando tanto o(a) profissional quanto às pacientes que procuram a Unidade Básica de Saúde (UBS) (OLIVEIRA MT e FERIGATO SH, 2019). Esses programas se mostram essenciais, uma vez que é sabido que os profissionais que mais identificam e atuam na ocorrência de violência doméstica são os(as) aqueles com formação específica para detecção e manejo desse tipo de violência (RODRIGUEZBLANES GM, et al., 2017).

Os programas de educação continuada também permitiriam a padronização da conduta frente à violência doméstica na APS por meio de protocolos para atuação dos (as) profissionais e direcionamento dos pacientes na rede de saúde. Com isso, foi apontado em diversos estudos que médicos(as) que trabalham em locais que dispõem desses recursos para a continuidade dos cuidados ao paciente lidam de forma mais expressiva frente à violência doméstica (RODRIGUEZ-BLANES GM, et al., 2017).

Somado a esse contexto, encontram-se os objetivos da Política Nacional da Atenção Básica (PNAB) no SUS, cujo foco está no desenvolvimento de ações que buscam gerar impactos nos condicionantes e determinantes de saúde de uma determinada comunidade. Desse modo, vários estudos contribuem para fomentar esse cenário do preparo e treinamento técnico do(a) médico(a) como sendo fundamental na prática e execução dessas políticas, assim como na entrega de cuidados fundamentais para com as vítimas na comunidade (OLIVEIRA MT e FERIGATO SH, 2019).

Uma das importantes consequências que permeiam a inexperiência dos(as) profissionais é a subnotificação. Notificar casos de violência doméstica constitui ato obrigatório em todo território nacional, em serviços públicos e privados, além de ocorrer de maneira sigilosa. A notificação visa fornecer informações epidemiológicas acuradas sobre a situação no Brasil que possam embasar políticas públicas para combater o problema (LEITE AC e FONTANELLA BJB, 2019). Mesmo assim, as taxas relatadas de violência doméstica 
nos instrumentos de notificação são muito inferiores à prevalência da situação relatada na literatura, indicando grande subnotificação (BORBUREMA TLR, et al., 2017).

Sendo consequência direta do despreparo dos profissionais, é possível traçar um paralelo entre as dificuldades técnicas, éticas e culturais que impactam na conduta médica e as dificuldades da mesma ordem que impactam nas notificações. Um deles é o desconhecimento legal da obrigatoriedade da notificação pelo profissional que atende a queixa, que pode acreditar que esta seria uma obrigação de um serviço especializado em violência doméstica, assim como pode acreditar ser outro serviço o responsável pela conduta desses casos (LEITE AC e FONTANELLA BJB, 2019).

O protocolo atualmente a ser seguido para notificar os casos contém 55 campos a serem preenchidos pelo médico. Seu título é Ficha de notificação / investigação individual, que acaba passando ao profissional da saúde a ideia de interrogação, causando grande desconforto a ele e à vítima.

A falta de informações sobre as consequências do preenchimento do documento faz com que haja hesitação em seu uso. Com isso, a qualificação dos(as) médicos(as) acerca dos termos existentes no documento e no Código Penal, além da simplificação da ficha de notificação, poderiam contribuir para amenização dos casos de repulsa ao preenchimento ao esclarecer e eliminar possíveis ambiguidades entre a atividade de notificar e denunciar (LEITE AC e FONTANELLA BJB, 2019).

Foram apontados na literatura formas de mitigar o desfalque na atuação em violência doméstica na APS, através da Política Nacional de Atenção Integral à Saúde da Mulher (PNAISM), da qual objetiva fomentar e implementar políticas que tenham como alvo mulheres vítimas de violência doméstica, fornecendo algumas propostas. Dentre elas, encontra-se a ideia de ampliação do número de profissionais atuantes da Estratégia de Saúde da Família qualificados em questões de gênero, além de ampliar o número de serviços de saúde com notificação de violências de gênero em 20\% (OLIVEIRA MT e FERIGATO SH, 2019).

Neste contexto, admite-se que o ramo da saúde, assim como profissionais médicos, possuem papel imprescindível no reconhecimento, prevenção e amparo às vítimas de violência doméstica, assim como é urgente a devida preparação desses em todos os aspectos, visto que a maioria das mulheres, em alguma fase da vida, comunica com o Serviço Nacional de Saúde (SNS) por diversos motivos (SILVA AR, 2018).

\section{CONSIDERAÇÕES FINAIS}

A violência doméstica contra a mulher é marcada por grande complexidade, invisibilidade e limitações, decorrentes de vários fatores. Por sua atuação como porta de entrada, a APS é fundamental para enfrentamento dessa temática. Notou-se pouco preparo dos(as) médicos(as) para identificar, notificar e acompanhar os casos de vítimas de violência, resultando em possível subnotificação, sendo assim, fundamental a capacitação continuada dos profissionais. Além disso, são necessárias políticas públicas em saúde mais eficazes e uma rede de serviços articulada, visando o rompimento do ciclo de violência, a articulação do cuidado e a garantia da integralidade da atenção.

\section{REFERÊNCIAS}

1. ARBOIT J, et al. Violência doméstica contra mulheres rurais: práticas de cuidado desenvolvidas por agentes comunitários de saúde. Saúde soc. São Paulo, 2018; 27(2): 506-517.

2. BORBUREMA TLR, et al. Violência contra mulher em contexto de vulnerabilidade social na Atenção Primária: registro de violência em prontuários. Rev Bras Med Fam Comunidade, 2017; 12(39): 1-13.

3. GARCIA LP, et al. Violência doméstica e familiar contra a mulher: estudo de casos e controles com vítimas atendidas em serviços de urgência e emergência. Cad. Saúde Pública, Rio de Janeiro, 2016; 32(4): 1-11.

4. LEITE AC, FONTANELLA BJB. Violência doméstica contra a mulher e os profissionais da APS: Predisposição para abordagem e dificuldades com a notificação. Revista Brasileira de Medicina de Família e Comunidade, 2019; 14(41): 2059.

5. LEITE FMC, et al. Violência contra a mulher e sua associação com o perfil do parceiro íntimo: estudo com usuárias da atenção primária. Rev. bras. epidemiol., 2018; 22: 1-14. 
6. LOPES JDS. Humanização do acolhimento à mulher vítima de violência doméstica: revisão sistemática a partir da promulgação da Lei Maria da Penha. Periódico do Núcleo de Estudos e Pesquisas sobre Gênero e Direito, 2016; $5(1): 282-302$.

7. LOURENÇO LM, COSTA DP. Violência entre Parceiros Íntimos e as Implicações para a Saúde da Mulher. Revista Interinstitucional de Psicologia, 2020; 13(1): 1-18.

8. MACHADO DF, et al. Abordagem da Violência contra a Mulher no Ensino Médico: um Relato de Experiência. Rev. bras. educ. med. Rio de Janeiro, 2016; 40(3): 511-520.

9. MACHADO MES, et al. Perception of health professionals about violence against women: a descriptive study. Online braz j nurs, 2017; 16(1): 209-217.

10. MENDONÇA CS, et al. Violência na Atenção Primária em Saúde no Brasil: uma revisão integrativa da literatura. Ciênc. saúde coletiva, Rio de Janeiro, 2020; 25(6): 2247-2257.

11. OLIVEIRA AMN, et al. Percepção dos profissionais de saúde frente às intervenções primárias: prevenindo a violência intrafamiliar. Texto Contexto Enferm, 2015; 24(2): 424-31.

12. OLIVEIRA MT, FERIGATO SH. A atenção às mulheres vítimas de violência doméstica e familiar: a construção de tecnologias de cuidado da terapia ocupacional na atenção básica em saúde. Cad. Bras. Ter. Ocup., 2019; 27(3): 508521.

13. PEREIRA-GOMES N, et al. Apoio social à mulher em situação de violência conjugal. Rev. salud pública, Bogotá, 2015; 17(6): 823-835.

14. RODRIGUEZ-BLANES GM, et al. Detección de violencia del compañero íntimo en atención primaria de salud y sus factores asociados. Gac Sanit, 2017; 31(5): 410-415.

15. SALIBA O, et al. Responsabilidade do profissional de saúde sobre a notificação de casos de violência doméstica. Rev. Saúde Pública, São Paulo, 2007; 41(3): 472-477.

16. SANTOS WJ, et al. Violência Doméstica Contra a Mulher Perpetrada por Parceiro Íntimo: Representações Sociais de Profissionais da Atenção Primária à Saúde. Rev Fund Care Online, 2018; 10(3): 770-777.

17. SIGNORELLI MC, et al. Domestic violence against women, public policies and community health workers in Brazilian Primary Health Care. Ciênc. saúde coletiva, 2018; 23(1): 93-102.

18. SILVA AR. Violência doméstica e segredo médico: o papel do médico de família. Revista Portuguesa de Medicina Geral e Familiar, 2018; 34(2): 101-103.

19. SPRAGUE S, et al. A scoping review of intimate partner violence educational programs for health care professionals. Women \& Health, 2018; 58(10): 1192-1206.

20. USTA J, TALEB R. Addressing domestic violence in primary care: what the physician needs to know. Libyan Journal of Medicine, 2014; 9: 1-7.

21. VIEIRA EM, HASSE M. Percepções dos profissionais de uma rede intersetorial sobre o atendimento a mulheres em situação de violência. Interface (Botucatu), Botucatu, 2017; 21(60): 51-62. 